\title{
The Challenges of Implementing Healthcare Technology and Innovation Across Europe and Beyond
}

\author{
Heli Laarmann \\ Ministry of Social Affairs of \\ Estonia \\ Tallinn, Estonia \\ heli.laarmann@sm.ee \\ Rodolphe Thiebaut \\ Universite de Bordeaux \\ Bordeaux, France \\ rodolphe.thiebaut@u-bordeaux.fr

\begin{abstract}
Public Health in the European Union is mainly a formal competence of the Member States. EU Treaties and Regulations have given EU gradually more mandate in past decades on issues of surveillance, epidemic intelligence, early warning and cross-border response coordination. In this context, sharing timely information on public health threats (fast and slow) to inform interventions at national and EU level, remains of great added value for all Member States. This depends on common standards, compatibility and interoperability of information systems. In this session, panellists will share their experience and recent digital health developments from the perspective of regional, national and international public health and discuss this in the light of developments in digital technology.
\end{abstract}

DPH Plenary Session

\author{
Clayton Hamilton \\ WHO Europe \\ Geneva, Switzerland \\ hamiltonc@who.int \\ Umair A. Shah \\ Harris County Public Health \\ Houston, Texas USA \\ ushahmd@gmail.com \\ Patty Kostkova \\ UCL IRDR Centre for Digital \\ Public Health in Emergencies \\ London, United Kingdom \\ P.kostkova@ucl.ac.uk
}

\author{
Arnold Bosman \\ Transmissable \\ Utrecht, Netherlands \\ arnold.bosman@transmissible.eu \\ Caroline Wood \\ UCL IRDR Centre for Digital \\ Public Health in Emergencies \\ London, United Kingdom \\ Caroline.wood@ucl.ac.uk
}

\section{KEYWORDS}

Digital, Health, Innovation, Technologies, Healthcare, Public Health, Systems

Permission to make digital or hard copies of part or all of this work for personal or classroom use is granted without fee provided that copies are not made or distributed for profit or commercial advantage and that copies bear this notice and the full citation on the first page. Copyrights for third-party components of this work must be honored. For all other uses, contact the Owner/Author. DPH' 19, November 20-23, 2019, Marseille, France (C) 2019 Copyright is held by the owner/author(s). ACM ISBN 978-1-4503-7208-4/19/11.

DOI: https://doi.org/10.1145/3357729.3365106 